\title{
Reverse Saturable Absorption in 5,10,15,20-Tetra(4-pyridyl)-21H,23H-porphyrin with Ruthenium Outlying Complexes
}

\author{
Newton M. Barbosa Neto, ${ }^{*, a}$ Samuel L. Oliveira, ${ }^{b}$ Ilde Guedes, ${ }^{b, c}$ Luis R. Dinelli, ${ }^{d}$ Lino Misoguti, \\ Cleber R. Mendonça, ${ }^{b}$ Alzir A. Batista ${ }^{e}$ and Sergio C. Zílio ${ }^{b}$ \\ ${ }^{a}$ Instituto de Física, Universidade Federal de Uberlândia, CP 593, 38400-902 Uberlândia-MG, Brazil \\ ${ }^{b}$ Instituto de Física de São Carlos, Universidade de São Paulo, CP 369, 13560-970 São Carlos-SP, Brazil \\ ${ }^{c}$ Departamento de Física, Universidade Federal do Ceará, CP 6030, 60455-970 Fortaleza-CE, Brazil \\ ${ }^{d}$ Fundação Educacional de Barretos, Av. Prof. Frade Monte, 389, 14783-226 Barretos-SP, Brazil \\ ${ }^{e}$ Departamento de Química, Universidade Federal de São Carlos, BR-13565-905 São Carlos-SP, Brazil
}

\begin{abstract}
Modificações no sinal de absorção de estado excitado da 5,10,15,20-tetra(4-piridil)-21H,23Hporfirina, provocadas tanto pela substituição do íon central quanto pela adição de grupos periféricos, são investigadas empregando-se pulsos laser de $5 \mathrm{~ns}$ com $532 \mathrm{~nm}$, juntamente com medidas de absorção linear e tempo de decaimento da fluorescência. A absorção saturada reversa (RSA) aumenta consideravelmente quando os íons $\mathrm{H}^{+}$são substituídos pelo $\mathrm{Zn}^{2+}$ na posição central do anel porfirínico. Contudo, esta diminui quando os grupos $\mathrm{RuCl}_{2}(\mathrm{CO})\left(\mathrm{PPh}_{3}\right)_{2} \mathrm{e}$ $\mathrm{RuCl}_{2}(\mathrm{CO})(\mathrm{dppb})$ são ligados através dos anéis piridínicos às posições periféricas da porfirina, tanto para a base livre quanto para a zinco porfirina. Um modelo teórico baseado no diagrama de Jablonski foi usado para verificar qual a principal causa da diminuição do sinal de RSA provocada pelos grupos de rutênio.
\end{abstract}

Investigations on the excited state absorption signal of 5,10,15,20-tetra(4-pyridyl)-21H,23Hporphyrin, modified by either changing the central ion or adding peripheral groups, were performed using $5 \mathrm{~ns}$ laser pulses at $532 \mathrm{~nm}$, in association with linear absorbance and fluorescence decay time measurements. The reverse saturable absorption (RSA) increases remarkably when $\mathrm{Zn}^{2+}$ replaces $\mathrm{H}^{+}$at the central position of the porphyrin ring. However, it decreases when $\mathrm{RuCl}_{2}(\mathrm{CO})\left(\mathrm{PPh}_{3}\right)_{2}$ and $\mathrm{RuCl}_{2}(\mathrm{CO})(\mathrm{dppb})$ groups are attached at outlying positions through the pyridine rings, for both the free base and zinc porphyrins. A theoretical model based on Jablonski diagram was used to verify the main reason for the decrease on the RSA signal caused by ruthenium groups.

Keywords: porphyrins, ruthenium complexes, optical properties, reverse saturable absorption

\section{Introduction}

In the last few decades, special attention has been given to the investigation of nonlinear optical properties of $\pi$-conjugated macrocyclic molecules, due to their potential application in photonic devices. ${ }^{1}$ Since these compounds present reverse saturable absorption (RSA), they are potential candidates to be used as optical limiting materials. ${ }^{2-4} \mathrm{RSA}$ is a resonant nonlinear absorption effect that arises when the absorption cross-section from an excited state up to a higher excited state is larger than the

*e-mail: newton@infis.ufu.br absorption cross-section from the ground state to it. ${ }^{2}$ RSA efficiency depends mainly on the ratio between excited and ground state absorption cross-sections $\left(\sigma_{\text {exc }} / \sigma_{\mathrm{g}}\right)$ and on the time the population remains in the excited state.

Among macrocyclic molecules, porphyrin complexes have deserved special attention because they present strong nonlinear signal, which can be further enhanced by modifying their structures. This can be accomplished by changing their central ion, ${ }^{5}$ adding groups to outlying positions ${ }^{6,7}$ or adding axial ligands to ions at the central part of the ring. ${ }^{8}$ Porphyrins are aromatic macrocyclics, formed by four pyrrole rings connected by unsaturated methylene bridges. In metal porphyrins, a central ion is 
linked to the nitrogen atoms of the ring. ${ }^{9}$ In particular, 5,10,15,20-tetra(pyridyl)-21H,23H-porphyrin is formed by four pyridyl groups attached to mesocarbons of the macrocycle, as shown in Figure 1.

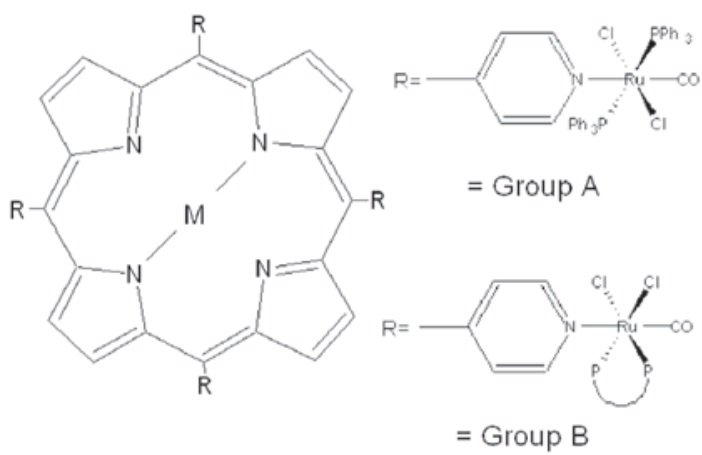

Figure 1. Molecular structure of the 5,10,15,20-tetra(pyridyl)-21H,23Hporphyrin. $\mathrm{R}$ represents the peripheral groups linked to the pyridine rings: group $\mathrm{A}=\mathrm{RuCl}_{2}(\mathrm{CO})\left(\mathrm{PPh}_{3}\right)_{2}$ or group $\mathrm{B}=\mathrm{RuCl}_{2}(\mathrm{CO})(\mathrm{dppb}) . \mathrm{PPh}_{3}=$ triphenylphosphine, $\mathrm{dppb}=\mathrm{P}-\mathrm{P}=$ bis (diphenylphosphine)butane. $\mathrm{M}$ represents the central ions: $2 \mathrm{H}^{+}$or $\mathrm{Zn}^{2+}$.

The RSA effect has been investigated in several porphyrins: basket handle porphyrins, ${ }^{10}$ tetraphenylporphyrins, ${ }^{11}$ and metalloporphyrins. ${ }^{5,12}$ Among the metalloporphyrins, those modified by ruthenium ions have been extensively studied due to their application as biological models. Most of these studies were performed with $\mathrm{Ru}^{\mathrm{II}}$ placed at the center of the porphyrin ring, either with or without axial ligands. ${ }^{13,14}$ This produces strong metal-to-ligand charge transfer bands in the visible region, ${ }^{13}$ which deeply influence the photophysical properties of porphyrins. There are some papers reporting on the basic characterization of porphyrins with ruthenium groups linked to outlying positions. ${ }^{15,16}$ However, none of them has reported on the influence of $\mathrm{Ru}^{\mathrm{II}}$ complexes at peripheral positions on the RSA performance of porphyrins.

Recently, we studied a class of porphyrins named 5,10,15,20-tetra(4-pyridyl)-porphyrin (TPyP) with different central ions. ${ }^{17,18} \mathrm{We}$ observed that the free base ( $\mathrm{H}_{2}$ TPyP) and the zinc species (ZnTPyP) present a RSA process due to both singlet and triplet excited states, with fluorescence and intersystem crossing times in the nanosecond time scale. This fact is of great importance for optical limiting purpose. Here we use $5 \mathrm{~ns}$ laser pulses at $532 \mathrm{~nm}$ in an optical limiting configuration, ${ }^{4}$ in association with linear absorbance and fluorescence decay time measurements. We investigate the influence of $\mathrm{Ru}^{\mathrm{II}}$ complexes, placed at the peripheral position of the ring, on the RSA efficiency of $\mathrm{H}_{2}$ TPyP and ZnTPyP. Two $\mathrm{Ru}^{\mathrm{II}}$ species were used: $\mathrm{RuCl}_{2}(\mathrm{CO})\left(\mathrm{PPh}_{3}\right)_{2}$ and $\mathrm{RuCl}_{2}(\mathrm{CO})$ (dppb), hereafter groups $\mathrm{A}$ and $\mathrm{B}$, respectively. $\mathrm{PPh}_{3}$ stands for triphenylphosphine and dppb for 1,4-bis(diphenylphosphine)butane. We observed that the RSA signal doubles for Zn-modified porphyrins, while it decreases when any of the $\mathrm{Ru}^{\mathrm{II}}$ groups is added. In order to determine the main factor responsible for the reduction on RSA signal caused by the presence of $\mathrm{Ru}^{\mathrm{II}}$ groups, we fitted the experimental data with a simplified five-energy-level model using as adjustable parameters the absorption crosssections of the first excited singlet and triplet states and the intersystem crossing time.

\section{Experimental}

\section{Samples}

$\mathrm{H}_{2}$ TPyP was synthesized by the following procedure: freshly distilled pyrrole $(9.9 \mathrm{~g}, 0.15 \mathrm{~mol})$ and 4pyridinecarboxaldehyde (16.1 g, $0.15 \mathrm{~mol})$ were added to $800 \mathrm{~mL}$ of refluxing reagent grade propionic acid. After refluxing for $1.5 \mathrm{~h}$, the solution was cooled down to room temperature and filtered, and the filter cake was washed thoroughly with methanol. After a hot water wash, the resulting purple crystals were dried in vacuum to remove absorbed acid. The $\mathrm{H}_{2}$ TPyP was purified on an alumina column using chloroform as a solvent and 5\% methanolchloroform as an eluent to yield $2.68 \mathrm{~g}$ (14\%).

ZnTPyP was synthesized according to the procedure described in reference 19 with the following modifications: $0.216 \mathrm{~g}\left(3.5 \times 10^{-4} \mathrm{~mol}\right)$ of the $\mathrm{H}_{2}$ TPyP and $0.173 \mathrm{~g}(8.7 \times$ $10^{-4} \mathrm{~mol}$ ) of zinc acetate were dissolved in a mixture of $20 \mathrm{~mL}$ of acetic acid and $20 \mathrm{~mL}$ of dimethylformamide under reflux. Yield: $0.238 \mathrm{~g}(92 \%)$.

The $\mathrm{Ru}^{\mathrm{II}}$ porphyrin complexes were synthesized under argon by reaction of $\mathrm{H}_{2}$ TPyP with $\left[\mathrm{RuCl}_{2}(\mathrm{CO})\right.$ $\left.\left(\mathrm{PPh}_{3}\right)_{2}(\mathrm{DMF})\right]^{20}$ or $\left[\mathrm{Ru}_{2} \mathrm{Cl}_{4}(\mathrm{CO})_{2}(\mathrm{dppb})_{3}\right]^{21}$ to give group $\mathrm{A}$ and group $\mathrm{B}$ complexes, respectively. The solutions were stirred for $4 \mathrm{~h}$ and their volume was then reduced by approximately $90 \%$. The solutions were then filtered and the filter cake was washed thoroughly with ethyl ether. Later, the powder obtained was dried in vacuum to give the desired compound. Thus, using the described procedure we synthesized $\left[\mathrm{H}_{2} \mathrm{TPyP}\left\{\mathrm{RuCl}_{2}(\mathrm{CO})\left(\mathrm{PPh}_{3}\right)_{2}\right\}_{4}\right]$ using $20 \mathrm{mg}$ $\left(3.23 \times 10^{-5} \mathrm{~mol}\right)$ of $\mathrm{H}_{2}$ TPyP with $95 \mathrm{mg}\left(1.29 \times 10^{-4} \mathrm{~mol}\right)$ of $\left[\mathrm{RuCl}_{2}(\mathrm{CO})\left(\mathrm{PPh}_{3}\right)_{2}(\mathrm{dmf})\right]$ in $20 \mathrm{~mL}$ of dichloromethane. Yield: 64\% (70 mg); Exp. (Calc.), \%C = 62.68 (63.71); $\% \mathrm{H}=4.33(4.24) ; \% \mathrm{~N}=3.72(3.23) ; v(\mathrm{CO}), 1957 \mathrm{~cm}^{-1}$; ${ }^{31} \mathrm{P}\left\{{ }^{1} \mathrm{H}\right\}, \delta 30.4$, singlet, in $\mathrm{CH}_{2} \mathrm{Cl}_{2}$ as solvent.

$\left[\mathrm{H}_{2} \mathrm{TPyP}\left\{\mathrm{RuCl}_{2}(\mathrm{CO})(\mathrm{dppb})\right\}_{4}\right]$ was synthesized using $20 \mathrm{mg}\left(3.23 \times 10^{-5} \mathrm{~mol}\right)$ of $\mathrm{H}_{2}$ TPyP and $119.5 \mathrm{mg}(6.7 \times$ $\left.10^{-5} \mathrm{~mol}\right)$ of $\left[\mathrm{Ru}_{2} \mathrm{Cl}_{4}(\mathrm{CO})_{2}(\mathrm{dppb})_{3}\right]$. Yield: $65 \%(65 \mathrm{mg})$; Exp. (Calc), \% $=59.74$ (59.93); \% H = 4.55 (4.51); 
$\% \mathrm{~N}=3.71(3.58) ; v(\mathrm{CO}), 1956 \mathrm{~cm}^{-1} ;{ }^{31} \mathrm{P}\left\{{ }^{1} \mathrm{H}\right\}, \delta 44.20$ and $\delta$ 25.93, doublet, in $\mathrm{CH}_{2} \mathrm{Cl}_{2}$ as solvent.

ZnTPyP-A was obtained from the reaction of $10 \mathrm{mg}$ of ZnTPyP $\left(1.47 \times 10^{-5} \mathrm{~mol}\right)$ with $43.1 \mathrm{mg}\left(5.88 \times 10^{-5}\right.$ mol) of $\left[\mathrm{RuCl}_{2}(\mathrm{CO})\left(\mathrm{PPh}_{3}\right)_{2}(\mathrm{dmf})\right]$ in $20 \mathrm{~mL}$ of $\mathrm{CH}_{2} \mathrm{Cl}_{2}$. The mixture was stirred for $4 \mathrm{~h}$, after what the volume of the reaction mixture was reduced to about $2 \mathrm{~mL}$ and ether was added to precipitate a violet solid, which was well washed with ether. Yield: $36.10 \%$ (19 mg); Exp. (Calc.), $\% \mathrm{C}=61.40(61.36) ; \% \mathrm{H}=3.98(3.95) ; \% \mathrm{~N}=3.14$ (3.03); $v(\mathrm{CO}), 1960 \mathrm{~cm}^{-1} ;{ }^{31} \mathrm{P}\left\{{ }^{1} \mathrm{H}\right\}, \delta 30.1$, singlet, in $\mathrm{CH}_{2} \mathrm{Cl}_{2}$ as solvent.

Zn-TPyP-B was obtained by the same procedure, using the binuclear $\left[\mathrm{Ru}_{2} \mathrm{Cl}_{4}(\mathrm{CO})_{2}(\mathrm{dppb})_{3}\right]$ in 1:2 proportion. Yield: $79 \%$ (42 mg); Exp.(Calc.), \% C = $58.60(58.74) ; \% \mathrm{H}=4.36$ (4.40); \% $=3.51$ (3.72); $v(\mathrm{CO}), 1956 \mathrm{~cm}^{-1} ;{ }^{31} \mathrm{P}\left\{{ }^{1} \mathrm{H}\right\}, \delta$ 44.61 and $\delta$ 25.36, doublet, in $\mathrm{CH}_{2} \mathrm{Cl}_{2}$ as solvent.

\section{Fluorescence decay times}

Fluorescence decay times were obtained pumping the samples with a 70-ps laser pulse at $532 \mathrm{~nm}$, delivered by a Q-switch Nd:YAG laser, and collecting the signal with a fast detector with a rise time of $0.5 \mathrm{~ns}$, coupled to an optical fiber. The signal was acquired and processed by a $1 \mathrm{GHz}$ digital oscilloscope.

\section{Linear and nonlinear absorption measurements}

UV-Vis absorption spectra were obtained with a CARY-17 spectrophotometer, with samples dissolved in chloroform and placed in a $0.2 \mathrm{~cm}$ cell. Nonlinear absorption measurements were performed, with the solutions placed in a $1 \mathrm{~cm}$ cell, using the second harmonic of the Q-switched Nd:YAG laser system producing $5 \mathrm{~ns}$ pulses at a $5 \mathrm{~Hz}$ repetition rate. The $532 \mathrm{~nm}$ laser beam was focused using a $27 \mathrm{~cm}$ focal-length lens in an f/135 configuration. The $1 \mathrm{~cm}$ cell was used in nonlinear optical measurements to assure that the focal volume was completely located inside the sample. After passing through the sample, the beam was collected by a $6 \mathrm{~cm}$ focal-length lens into a photodiode detector, which avoids self-defocusing, plasma and/or cavity bubble scattering contributions. The incoming laser energy was adjusted using a half-wave plate placed between two crossed polarizers; the maximum incoming energy was around $3.5 \mathrm{~mJ}$. The linear transmittance, in the nonlinear absorption measurements, was adjusted at around $60 \%$ for all samples. This was performed to assure the same molecular population transfer from the ground to the excited state.

\section{Results and Discussion}

The absorption spectra of the $\mathrm{H}_{2}$ TPyP, $\mathrm{H}_{2}$ TPyP-A, $\mathrm{H}_{2}$ TPyP-B, ZnTPyP, ZnTPyP-A and ZnTPyP-B complexes are shown in Figure $2 a$ and $2 b$, where the characteristic $B$ band (Soret band) located around $400 \mathrm{~nm}$ and Q bands located between 470 and $700 \mathrm{~nm}$ are observed. The Soret band is related to a strongly allowed $\pi-\pi^{*}$ electronic transition, while the Q band to a quasi-allowed one. In fact, the Q-band is enhanced by a vibronic coupling to the B band. ${ }^{9}$ For $\mathrm{H}_{2}$ TPyP, $\mathrm{H}_{2}$ TPyP-A and $\mathrm{H}_{2}$ TPyP-B, the Q-band presents four peaks: $\mathrm{Q}_{\mathrm{x}}(0,0)$ and $\mathrm{Q}_{\mathrm{y}}(0,0)$ with their respective vibronic overtones $\mathrm{Q}_{\mathrm{x}}(1,0)$ and $\mathrm{Q}_{\mathrm{y}}(1,0)$. On the other hand, a considerable modification on the spectrum is observed for zinc porphyrins, with the $\mathrm{Q}$ band presenting just two peaks: $\mathrm{Q}(0,0)$ and its respective vibrational overtone $\mathrm{Q}(1,0)$. This results from the increase of the overall molecular symmetry that changes from $\mathrm{D}_{2 \mathrm{~h}}$ to $\mathrm{D}_{4 \mathrm{~h}}$ when $\mathrm{Zn}^{+2}$ substitutes for $2 \mathrm{H}^{+} .{ }^{9}$ Also, just a small red shift in Soret and Q bands, caused by ruthenium outlying groups, is observed.
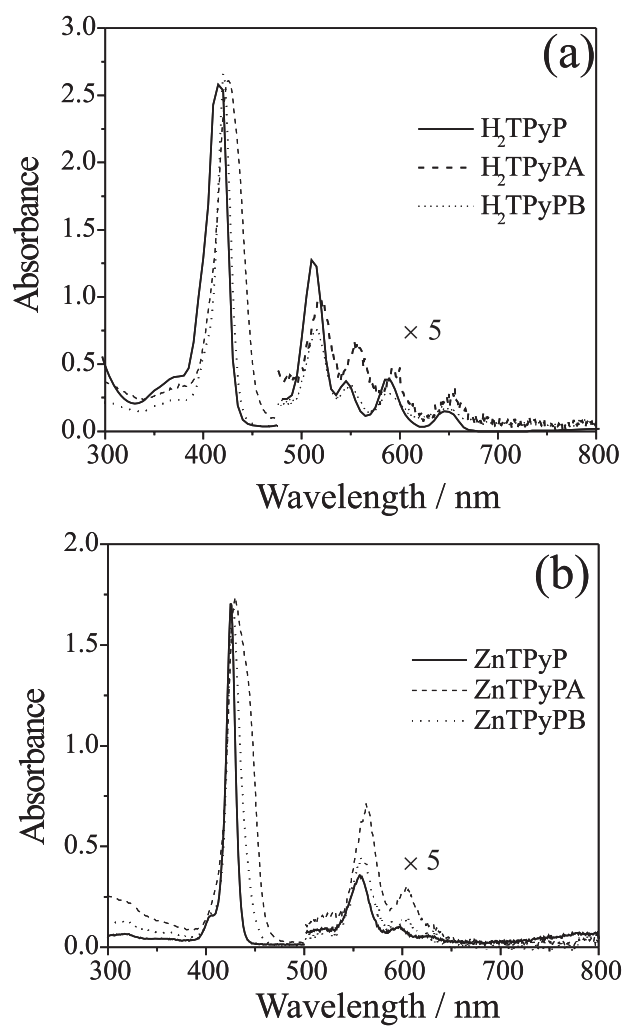

Figure 2. Absorption spectra of (a) $\mathrm{H}_{2}$ TPyP (solid line), $\mathrm{H}_{2}$ TPyPA (dashed line), $\mathrm{H}_{2}$ TPyPB (dotted line) and (b) ZnTPyP (solid line), ZnTPyPA (dashed line), ZnTPyPB (dotted line).

The RSA signals of the porphyrin complexes are shown in Figure $3 a$ and $3 b$. We observe that the efficiency of the reverse saturable absorption increases by a factor of two 
when $\mathrm{Zn}^{2+}$ ion replaces for $2 \mathrm{H}^{+}$, while it decreases when $\mathrm{Ru}^{\mathrm{II}}$ outlying groups are present, exhibiting a worthless signal for porphyrins with group A, for both $\mathrm{H}_{2} \mathrm{TPyP}$ and ZnTPyP. This can be observed from the figure of merit (FM) in Table 1, which is defined as the ratio between the minimum and the linear transmittance values.
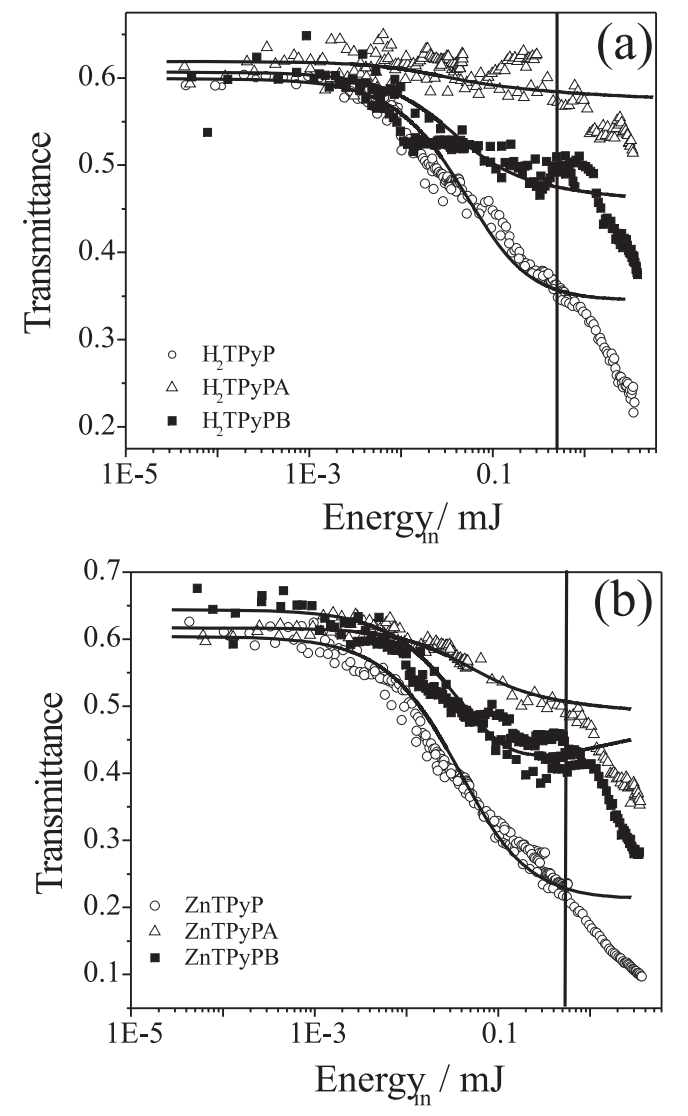

Figure 3. Reverse saturable absorption in porphyrin complexes. The solid lines represent the theoretical fitting obtained with the five-energy-level model.

The RSA mechanism is a resonant absorption effect involving ground and excited states, which can be understood, at nanosecond time scale, considering a five-energy-level diagram known as the Jablonski diagram, ${ }^{9}$ shown in Figure 4. It indicates the possible nonradiative and radiative processes that include intersystem crossing, internal conversion, radiative decay and excited state absorption.

Initially, light promotes the molecules from the ground state $S_{0}$ to the first excited singlet state $\left(S_{1}\right)$. From this state, the molecule can return back to the state $S_{0}$, be excited to the state $S_{2}$, or yet undergo an intersystem crossing relaxation to the state $\mathrm{T}_{1}$. From $\mathrm{T}_{1}$, the molecule can return to $S_{0}$ or, by absorbing another excitation photon, can be promoted to $T_{2}$. If sufficient population is transferred to $\mathrm{S}_{1}$ or $\mathrm{T}_{1}$, and the excited state absorption

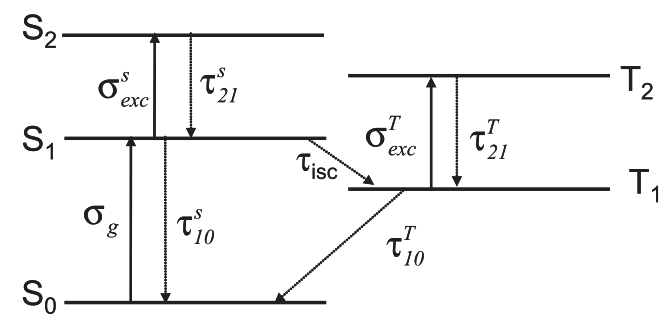

Figure 4. Jablonski diagram. $\mathrm{S}_{\mathrm{i}}$ represents the singlet states while $\mathrm{T}_{\mathrm{i}}$ represents the triplet states. $\sigma_{\text {exc }}^{\mathrm{S}}, \sigma_{\text {exc }}^{\mathrm{T}}$ are singlet and triplet excited state absorption cross-sections, respectively. $\sigma_{\mathrm{g}}$ is the ground state absorption cross-section and $\tau_{\text {isc }}$ is the intersystem crossing time.

cross-sections of these states are larger than the ground ones, RSA arises. In particular, for nanosecond pulses, RSA in porphyrin molecules is related to both singlet and triplet excited state absorption. Therefore, the efficiency of the RSA process depends on high $\sigma_{\text {exc }} / \sigma_{g}$ values and on the time the population remains in the lower excited state. To determine the main factor responsible for the reduction on RSA signal caused by the presence of $\mathrm{Ru}^{\mathrm{II}}$ groups, we adjusted the experimental results with a simplified fiveenergy-level model based on the Jablonski diagram.

In this model, the decay from state $\mathrm{T}_{1}$ to $\mathrm{S}_{0}$ is neglected once the triplet state $\left(\mathrm{T}_{1}\right)$ lifetime is in the order of some microseconds for porphyrins, being much slower than the pulse duration. Moreover, as the relaxation times of the higher excited state $\left(\mathrm{S}_{2}\right.$ and $\left.\mathrm{T}_{2}\right)$ are very fast, the population buildup is neglected for these states. Consequently, the rate equations used to describe the population dynamics are

$$
\begin{aligned}
& \frac{\mathrm{dn}_{\mathrm{S}_{0}}}{\mathrm{dt}}=-\mathrm{n}_{\mathrm{S}_{0}} \mathrm{~W}_{\mathrm{S}_{0} \rightarrow \mathrm{s}_{1}}+\frac{\mathrm{n}_{\mathrm{S}_{1}}}{\tau_{10}^{\mathrm{s}}} \\
& \frac{\mathrm{dn}_{\mathrm{S}_{1}}}{\mathrm{dt}}=\mathrm{n}_{\mathrm{S}_{0}} \mathrm{~W}_{\mathrm{S}_{0} \rightarrow \mathrm{S}_{1}}-\frac{\mathrm{n}_{\mathrm{S}_{1}}}{\tau_{10}^{\mathrm{s}}}-\frac{\mathrm{n}_{\mathrm{S}_{1}}}{\tau_{\text {isc }}}
\end{aligned}
$$

$\frac{\mathrm{dn}_{\mathrm{T}_{1}}}{\mathrm{dt}}=\frac{\mathrm{n}_{\mathrm{S}_{1}}}{\tau_{\text {isc }}}$

where $\mathrm{W}_{\mathrm{S}_{0} \rightarrow \mathrm{s}_{1}}=\frac{\sigma_{\mathrm{g}} \mathrm{I}}{\mathrm{h} v}$ is the upward transition rate, $\tau_{\text {isc }}$ is the intersystem crossing time, and $\tau_{10}^{\mathrm{S}}$ is the relaxation time from the first excited singlet state to the ground state. Besides, $\tau_{10}^{\mathrm{S}}$ is related to $\tau_{\text {isc }}$ through the relation $\tau_{\mathrm{f}}^{-1}=$ $\tau_{\text {isc }}^{-1}+\tau_{10}^{\mathrm{S}-1}$, where $\tau_{\mathrm{f}}$ is the measured fluorescence time. Beer's law equation, which governs the change in the pulse intensity as it propagates through the sample, is given by

$\frac{\mathrm{dI}}{\mathrm{dz}}=-\mathrm{I}\left(\mathrm{n}_{\mathrm{S}_{0}} \sigma_{\mathrm{g}}+\mathrm{n}_{\mathrm{S}_{1}} \sigma_{\text {exc }}^{\mathrm{S}}+\mathrm{n}_{\mathrm{T}_{1}} \sigma_{\mathrm{exc}}^{\mathrm{T}}\right) \mathrm{N}$ 
Table 1. Spectroscopic parameters and figure of merit for $\mathrm{H}_{2} \mathrm{TPyP}$ and ZnTPyP complexes

\begin{tabular}{|c|c|c|c|c|c|c|}
\hline & $\mathrm{H}_{2} \mathrm{TPyP}$ & $\mathrm{H}_{2}$ TPyP-A & $\mathrm{H}_{2}$ TPyP-B & ZnTPyP & ZnTPyP-A & ZnTPyP-B \\
\hline$\sigma_{\mathrm{g}} / \mathrm{cm}^{2}$ & $1.6 \times 10^{-17}$ & $4.8 \times 10^{-17}$ & $2.7 \times 10^{-17}$ & $2.1 \times 10^{-17}$ & $2.3 \times 10^{-17}$ & $2 \times 10^{-17}$ \\
\hline$\sigma_{\text {exc }}^{\mathrm{S}} / \mathrm{cm}^{2}$ & $4 \times 10^{-17}$ & $5 \times 10^{-17}$ & $3.3 \times 10^{-17}$ & $5 \times 10^{-17}$ & $3 \times 10^{-17}$ & $4 \times 10^{-17}$ \\
\hline$\sigma_{\mathrm{exc}}^{\mathrm{T}} / \mathrm{cm}^{2}$ & $2.1 \times 10^{-17}$ & $3 \times 10^{-17}$ & $4 \times 10^{-17}$ & $3.8 \times 10^{-17}$ & $2.8 \times 10^{-17}$ & $2.4 \times 10^{-17}$ \\
\hline$\tau_{\mathrm{f}} / \mathrm{ns}$ & 8 & 3 & 5 & 2 & $\leq 1$ & $\leq 1$ \\
\hline$\tau_{\mathrm{isc}} / \mathrm{ns}$ & 14 & 3 & 6 & 6 & $\approx 1$ & $\approx 1$ \\
\hline$\sigma_{\mathrm{exc}}^{\mathrm{s}} / \sigma_{\mathrm{g}}$ & 2.5 & 1 & 1.2 & 2.4 & 1.3 & 2 \\
\hline$\sigma_{\text {exc }}^{\mathrm{T}} / \sigma_{\mathrm{g}}$ & 1.3 & 1.2 & 1.5 & 1.8 & 1.2 & 1.2 \\
\hline $\mathrm{FM}$ & 2.7 & 1.1 & 1.6 & 6 & 1.7 & 2.1 \\
\hline
\end{tabular}

where $\mathrm{N}$ is the molecular concentration and $\mathrm{I}$ is the temporal Gaussian intensity profile. $\sigma_{\mathrm{g}}, \sigma_{\text {exc }}^{\mathrm{S}}$ and $\sigma_{\mathrm{exc}}^{\mathrm{T}}$ are the absorption cross-sections for ground, first singlet and first triplet excited state, respectively. The transmittance is obtained from the ratio between incoming and outgoing pulse intensities.

After performing numerical calculations with equations 1 and 2, we were able to obtain the excited state absorption cross-sections and the intersystem crossing time as adjustable parameters. The ground state absorption cross section and fluorescence decay time were obtained from absorbance spectra and fluorescence decay time measurements. The spectroscopic parameters values are listed in Table 1.

In order to test the reliability of the procedure we performed fittings for $\mathrm{H}_{2}$ TPyP and ZnTPyP with no ruthenium groups using the spectroscopic parameters obtained from references 17 and 18. The fittings (solid lines) are also shown in Figure 3. A discrepancy between experimental and theoretical fittings for all samples is observed for incoming energies above $0.5 \mathrm{~mJ}$. This is explained by the strong cavitation bubble and thermal lens refraction contributions present in high energy regime. ${ }^{22}$

The increase in RSA performance caused by introducing $\mathrm{Zn}^{2+}$ in the porphyrin ring was expected and has already been reported for other porphyrins. ${ }^{4,5,11}$ This enhancement is attributed to the well known heavy atom effect. ${ }^{23-25}$ Adding heavy atoms to the porphyrin structure enhances the spin-orbit coupling, increasing the intersystem crossing rate. This effect leads to an increase of the excited triplet state population, which in general presents a higher excited state absorption cross-section. ${ }^{23}$ From Table 1 we observe that $\mathrm{Zn}^{2+}$ increases the ratio between the first triplet excited and ground state absorption cross-sections. However, the increase in the ratio of absorption cross-sections is smaller than that observed for the figure of merit. The explanation for this difference comes from the fact that in calculating the figure of merit we considered the minimum transmittance that has contributions from other effects.

On the other hand, when $\mathrm{Ru}^{\mathrm{II}}$ complexes are attached to the pyridyl groups of both $\mathrm{H}_{2}$ TPyP and ZnTPyP, we observe a deleterious effect on the RSA signal, being worst for group A. The results obtained from the theoretical fitting show that the $\mathrm{Ru}^{\mathrm{II}}$ complexes reduce the $\sigma_{\text {exc }} / \sigma_{g}$ ratio at $532 \mathrm{~nm}$, mainly due to the population of the first singlet excited state. Although the outlying groups reduce the fluorescence time, they still are in the order of a few nanoseconds, and this points out that the principal contribution comes from the reduction on the absorption cross-section ratios. Moreover, the fact that the RSA signal decreases for both $\mathrm{H}_{2}$ TPyP and ZnTPyP indicates that the deleterious influence of ruthenium groups is independent of the central ion, at least for closed shell central ions in regular porphyrins. ${ }^{9}$

\section{Conclusions}

We investigated the influence of peripheral $\mathrm{Ru}^{\mathrm{II}}$ complexes on the RSA performance of $\mathrm{H}_{2} \mathrm{TPyP}$ and ZnTPyP, both regular type porphyrins. We observed that the RSA signal decreases when $\mathrm{Ru}^{\mathrm{II}}$ groups are attached to peripheral position of the porphyrins. The increase in the RSA observed for ZnTPyP without ruthenium groups agrees with other works reported in the literature, being explained by means of the heavy-atom effect. We observed from a simple theoretical model that the reduction of RSA signal due to the presence of peripheral groups is caused by the reduction of the ratio between excited and ground states absorption cross-sections, mainly for singlet excited state.

Theoretical fittings also show that for high energy regime the optical limiting behavior of porphyrins should have contributions from additional effects besides RSA. 
Probably, two of the most important additional processes to the optical limiting mechanisms are the scattering caused by cavitation bubbles and the thermal nonlinear refraction. The results also indicate that both ZnTPyP and $\mathrm{H}_{2}$ TPyP are promising candidates to be applied as optical limiting materials, once they have a very small energy threshold. However, molecular engineering strategies are required in order to increase the ratio between the absorption cross-sections.

\section{Acknowledgments}

The authors thank Fundação de Amparo à Pesquisa do Estado de São Paulo (FAPESP) and Conselho Nacional de Pesquisa (CNPq) for financial support. Dr. I. Guedes is grateful to the Departamento de Física of Universidade Federal do Ceará and FAPESP (grant \# 2004/02067-6) for support during his stay at the Instituto de Física de São Carlos - USP

\section{References}

1. Potenza, G.; Sona, A.; Nuovo Cimento 1965, 38, 1438.

2. Perry, J. W. In Nonlinear Optics of Organic Molecules and Polymers, Nalwa, H. S.; Miyta, S., eds.; CRC Press: Boca Raton, 1997, pp. 813.

3. Shirk, J. S.; Pong, R. G. S.; Bartolli, F. J.; Snow, A. W.; Appl. Phys. Lett. 1993, 63, 1880.

4. Calvete, M.; Yang, G. Y.; Hanack, M.; Synth. Met. 2004, 141, 231.

5. Mishra, S. R.; Rawat, H. S.; Laghate, M.; Opt. Commun. 1998, 147, 328.

6. Su, W.; Cooper, T. M.; Brant, M. C.; Chem. Mater. 1998, 10, 1212.

7. Mcewan, K. J.; Bourhill, G.; Robertson, J. M.; J. Nonlinear Phys. Mater. 2000, 9, 451.

8. Kiran, P. P.; Reddy, D. R.; Maiya, B. G.; Dharmadhikari, A. K.; Kumar, G. R.; Desai, N. R.; Appl. Optics 2002, 41, 7631.
9. Kalyanasundaram, K.; Photochemistry of Polypyridine and Porphyrin Complexes, Academic Press: San Diego, 1992.

10. Sevian, A.; Ravikanth, M.; Kumar, G. R.; Chem. Phys. Lett. 1996, 263, 241.

11. Blau, W.; Byrne, H.; Dennis, W. M.; Kelly, J. M.; Opt. Commun. 1985, 56, 25.

12. Martin, R. B.; Li, H.; Gu, L.; Kumar, S.; Sanders, C. M.; Sun, Y.-P.; Opt. Mater. 2005, 27, 1340.

13. Rodriguez, J.; McDowell, L.; Holten, D.; Chem. Phys. Lett. 1988, 147, 235.

14. Antipas, A.; Buchler, J. W.; Gouterman, M.; Smith, P.D.; J. Am. Chem. Soc. 1978, 100, 3015.

15. Steiger, B.; Shi, C.; Anson, F.C.; Inorg. Chem. 1993, 32, 2107.

16. Araki, K.; Angnes, L.; Azevedo, C.M.N.; Toma, H. E.; J. Electroanal. Chem. 1995, 397, 205.

17. Barbosa Neto, N. M.; De Boni, L.; Rodrigues Jr., J. J.; Misoguti, L.; Mendonça, C. R.; Dinelli, L. R.; Batista, A. A.; Zílio, S. C.; J. Porphyr. Phthalocyanines 2003, 7, 452.

18. Barbosa Neto, N. M.; De Boni, L.; Mendonça, C. R.; Misoguti, L.; Queiroz, S. L.; Dinelli, L. R.; Batista, A. A.; Zílio, S. C.; J. Phys. Chem. B 2005, 109, 17340.

19. Fleischer, E. B.; Inorg. Chem. 1962, 1, 493.

20. Wohnrath, K.; Batista, A. A.; Ferreira, A. G.; ZukermanSchpector, J.; De Oliveira, L. A. A.; Castellano, E. E.; Polyhedron 1998, 17, 2013

21. Bressan, M.; Rigo, P.; Inorg. Chem. 1975, 14, 2286.

22. Sendhil, K.; Vijayan, C.; Kothiyal M. P.; Opt. Laser Technol. 2006, 38, 512.

23. Perry, J. W.; Mansour, K.; Marder, S. R.; Perry, K. J.; Alvarez Jr., D.; Choong, I.; Opt. Lett. 1994, 19, 625.

24. Shirk, J. S.; Pong, R. G. S.; Bartolli, F. J.; Snow, A. W.; Appl. Phys. Lett. 1993, 63, 1880.

25. Brannon, J. H.; Magde, D.; J. Am. Chem. Soc. 1980, 102, 62.

Received: October 4, 2005

Published on the web: September 26, 2006

FAPESP helped in meeting the publication costs of this article. 